\title{
OFICINA DE REÚSO DE EFLUENTES COMO FERRAMENTA DE SENSIBILIZAÇÃO AMBIENTAL COM AGRICULTORES NO SEMIÁRIDO
}

\author{
Wilza da Silva Lopes ${ }^{1}$ \\ Gleydson Kleyton Moura Nery² \\ Adriana Guedes Magalhães ${ }^{3}$ \\ Antonio Carlos Pires de Mello ${ }^{4}$
}

Resumo: O reúso agrícola do esgoto tratado é uma alternativa viável principalmente em áreas que apresentam problemas de escassez hídrica. Deste modo, a presente pesquisa teve por objetivo avaliar a percepção de agricultores sobre o reúso de esgoto tratado. Realizou-se uma oficina de reúso no município de Assunção - PB, consistindo no levantamento de informações sobre as práticas de reúso por eles realizadas, composição do esgoto, exposição de informações para prática do reúso, e por fim compartilhamento de experiências. Nesse estudo foi possível perceber que os agricultores já aplicam o reúso de águas cinzas para as atividades de uso menos nobre, mas nada voltado para o reúso de esgoto ou para aplicação na agricultura.

Palavras-chave: Esgoto; Águas Cinzas; Reúso Agrícola; Percepção; Zona Rural.

Abstract: The agricultural reuse of treated sewage is a viable alternative especially for areas with water scarcity problems. Therefore, this research aimed to evaluate farmers' perception of wastewater reuse. A workshop about sewage reuse practices was performed in Assunção city (Paraíba- Brazil). First, the farmers were asked about their practices of sewage reuse and, the composition of sewage. Then were exposed information about the use of treated sewage in agriculture and finally a shared personal experiences of sewage reuse. It was possible to notice that farmers already apply the reuse of greywater, but not for important activities, with application in agriculture.

Keywords: Sewage; Greywater; Agricultural Reuse; Perception; Rural Population.

${ }^{1}$ Instituto Nacional do Semiárido. E-mail: wilza.lopes@insa.gov.br, Link para o Lattes: http://lattes.cnpq.br/7520507366596799

2 Instituto Nacional do Semiárido. E-mail: gleydson.nery@insa.gov.br, Link para o Lattes: http://lattes.cnpq.br/1792962325401744

3 Doutora em Engenharia Agrícola pela UFRPE. E-mail: agmguedes@gmail.com, Link para o Lattes: http://lattes.cnpq.br/6998947634177983

${ }^{4}$ Programa de Aplicação de Tecnologias Apropriadas (PATAC). E-mail: tunicopatac@yahoo.com.br, Link para o Lattes: http://lattes.cnpq.br/7021233392301178

Revbea, São Paulo, V. 16, No 3: 224-236, 2021. 


\section{Introdução}

O Semiárido brasileiro possui uma extensão territorial de $1.128 .697 \mathrm{~km}^{2}$ distribuídos em 1.262 municípios, incluindo oito Estados na Região Nordeste (Ceará, Rio Grande do Norte, Paraíba, Pernambuco, Piauí, Alagoas, Sergipe e Bahia) e uma faixa que se estende no Norte de Minas Gerais. A precipitação pluviométrica do Semiárido Brasileiro é marcada pela variabilidade espaçotemporal, que associadas a baixas precipitações resulta em ocorrência frequentes de dias sem chuva, as chamadas secas (MEDEIROS et al., 2014; SUDENE, 2017).

Na região semiárida a precipitação anual média é igual ou inferior a $800 \mathrm{~mm}$, e cerca de $70 \%$ das chuvas se concentra entre os meses de janeiro à abril, com potencial de evaporação de até $700 \mathrm{~mm}$ anuais, e rios de características intermitentes. A alta taxa de evaporação associada a chuvas irregulares faz com que a região enfrente grandes problemas de déficit hídrico (ARAÚJO, 2012).

A demanda hídrica de água na agricultura a nível mundial é de cerca de $69 \%$, enquanto no Brasil quase metade da água consumida destina-se a agricultura irrigada. Apesar do grande consumo de água, a irrigação é fundamental para o desenvolvimento social, econômico e ambiental (PAZ et al., 2000).

Esse cenário é ainda mais agravante para regiões semiáridas devido ao déficit hídrico da região, havendo grandes dificuldades em atender a essa demanda nos períodos mais secos. Com isso, o esgoto apresenta-se como uma alternativa promissora para usos múltiplos no semiárido, especialmente para o reúso agrícola.

É importante destacar que apesar do reúso ser um conceito antigo, tendo relatos de práticas desde a Grécia Antiga, com a disposição de esgotos e sua utilização na irrigação, a prática de reúso na agricultura de forma planejada e sua importância para um desenvolvimento sustentável, ainda é uma das principais discussões atuais (BARROS et al., 2015).

Apesar das primeiras preocupações ambientais terem sido objeto de discussão na Conferência Mundial das Nações Unidas sobre Meio Ambiente em 1972, com o reconhecimento para melhoria da relação homem-natureza, uma mudança mais expressiva aqui no país veio a partir da ECO 92 . $\mathrm{Na}$ Agenda 21 foi dada uma importância especial para o uso e reciclagem de efluentes, para proteção da saúde e do meio ambiente como um todo, demonstrando assim a necessidade das práticas ambientais adequadas. Nesse documento também foi estabelecido ações para divulgação de técnicas seguras e higiênicas da água, e métodos corretos de disposição de esgoto na zona rural.

De acordo com o estabelecido na Agenda 21 é necessária uma ação coordenada que ultrapasse os limites da zona urbana, sendo importante o direcionamento adequado de disposição e tratamento para que os resíduos sólidos e líquidos não venham a contaminar os rios, riachos e lençóis 
subterrâneos de água, contribuindo para o surgimento de doenças de veiculação hídrica.

O esgoto apresenta um grande potencial para o reúso na agricultura devido a presença de nutrientes que são necessários às plantas. No entanto, sua utilização deve vir a ser aplicada de forma cuidadosa, com o tratamento adequado, para que o mesmo seja seguro. Para isso, os tratamentos devem preservar os nutrientes, reduzir a matéria orgânica e remover os microrganismos patogênicos. Isso porque, a exposição da população a esses microrganismos pode causar diversas doenças, seja por ingestão, inalação ou contato dérmico (METCALF; EDDY, 2016).

Para promover a sensibilização dos agricultores sobre a importância das práticas do reúso de esgoto na agricultura, é necessário buscar o conhecimento dos mesmo sobre a temática, mostrando as ações necessárias para realizá-lo de forma segura do ponto de vista da saúde humana, bem como apresentar as potencialidades desta prática para o desenvolvimento da região, principalmente para as populações que sofrem com a falta de água. Além disso, contribuir para o desenvolvimento de um indivíduo comprometido com a proteção do meio ambiente.

Segundo Romão et al. (2020) o processo de percepção começa com assimilação de uma informação ou algo presente no ambiente, ocorrendo de forma involuntária e contribuindo para a conscientização. Essa percepção ambiental está relacionada a forma como são apresentadas as questões ambientais, e sendo assim, atitudes proativas possibilitam as mudanças de paradigmas, de valores e a formação de um novo modelo de desenvolvimento mais consciente.

Dessa forma, o objetivo do presente trabalho foi investigar as principais percepções de agricultores da zona rural sobre as práticas de reúso de efluentes, bem como buscar sensibilizá-los sobre a importância das ações necessárias para o reúso agrícola do esgoto nas comunidades rurais.

\section{Material e métodos}

\section{Área de estudo}

O trabalho foi desenvolvido em uma parceria do Instituto Nacional do Semiárido (INSA) com o Programa de Aplicação de Tecnologias Apropriadas (PATAC) em outubro de $2019 \mathrm{com} 15$ agricultores da zona rural. A oficina foi realizada no município de Assunção localizada na região central do Estado da Paraíba, Mesorregião Borborema e Microrregião Cariri Ocidental. Limita-se ao norte com os municípios de Junco de Seridó e Tenório, à leste com Juazeirinho, sul com Taperoá e Oeste com Junco do Seridó e Salgadinho, como mostrado na Figura 1 (CPRM, 2005). Com base no censo IBGE (2010) o município possui uma área territorial de $132,1 \mathrm{~km}^{2}$, densidade demográfica de $27,86 \mathrm{hab} / \mathrm{km}^{2}$ e uma população estimada em 3990 para o ano de 2019 , sendo $72,4 \%$ residentes da zona urbana e $27,6 \%$ na zona rural. 


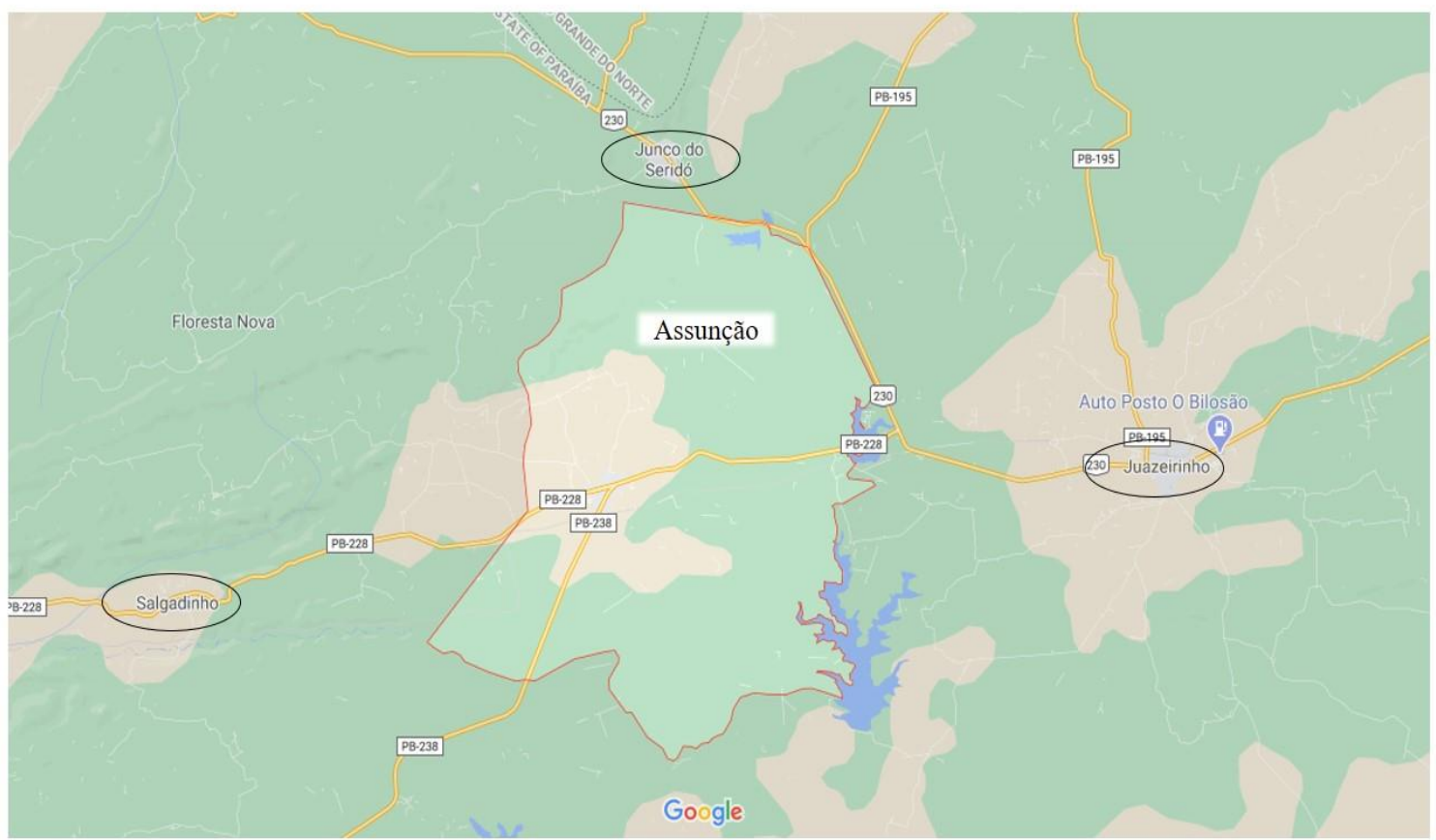

Figura 1: Localização geográfica do município de Assunção (PB).

Fonte: Google maps, 2020.

De um total de 692 domicílios particulares permanentes, 350 utilizam-se da rede geral de abastecimento de água, 185 usam poço ou nascente e 157 outra forma. Para um universo de 475 residências, $48,2 \%$ não possuíam banheiro ou sanitário. No ano de 2010 a população com esgotamento adequado foi de $46,7 \%$. A economia do município concentra-se principalmente no setor primário, através da agricultura e da pecuária com participação na faixa de $50,1 \%$ a $75 \%$. A agricultura apresenta como principais produtos agrícolas o algodão, o feijão, o milho, a mandioca e o arroz. Na pecuária, destacam-se as criações de caprinos e bovinos, com uma pequena participação na ovinocultura e avicultura (CPRM, 2005; IBGE, 2010).

\section{Procedimentos Metodológicos}

O estudo caracterizou-se como de cunho exploratório-descritivo, devido ao objetivo da pesquisa em observar os fenômenos e descrevê-los, assim como promover a elucidação de conceitos e informações que visem estimular desenvolvimento de competências (OLIVEIRA, 2011) aos sujeitos da pesquisa no reúso de efluentes para as atividades comuns do cotidiano.

Para o desenvolvimento da pesquisa, foram definidos três momentos: (i) caracterização das percepções dos agricultores sobre a temática, (ii) momento de socialização e reflexão dos conhecimentos construídos e (iii) sensibilização ambiental sobre a gestão e manejo dos efluentes como recursos para a comunidade (Figura 2). 


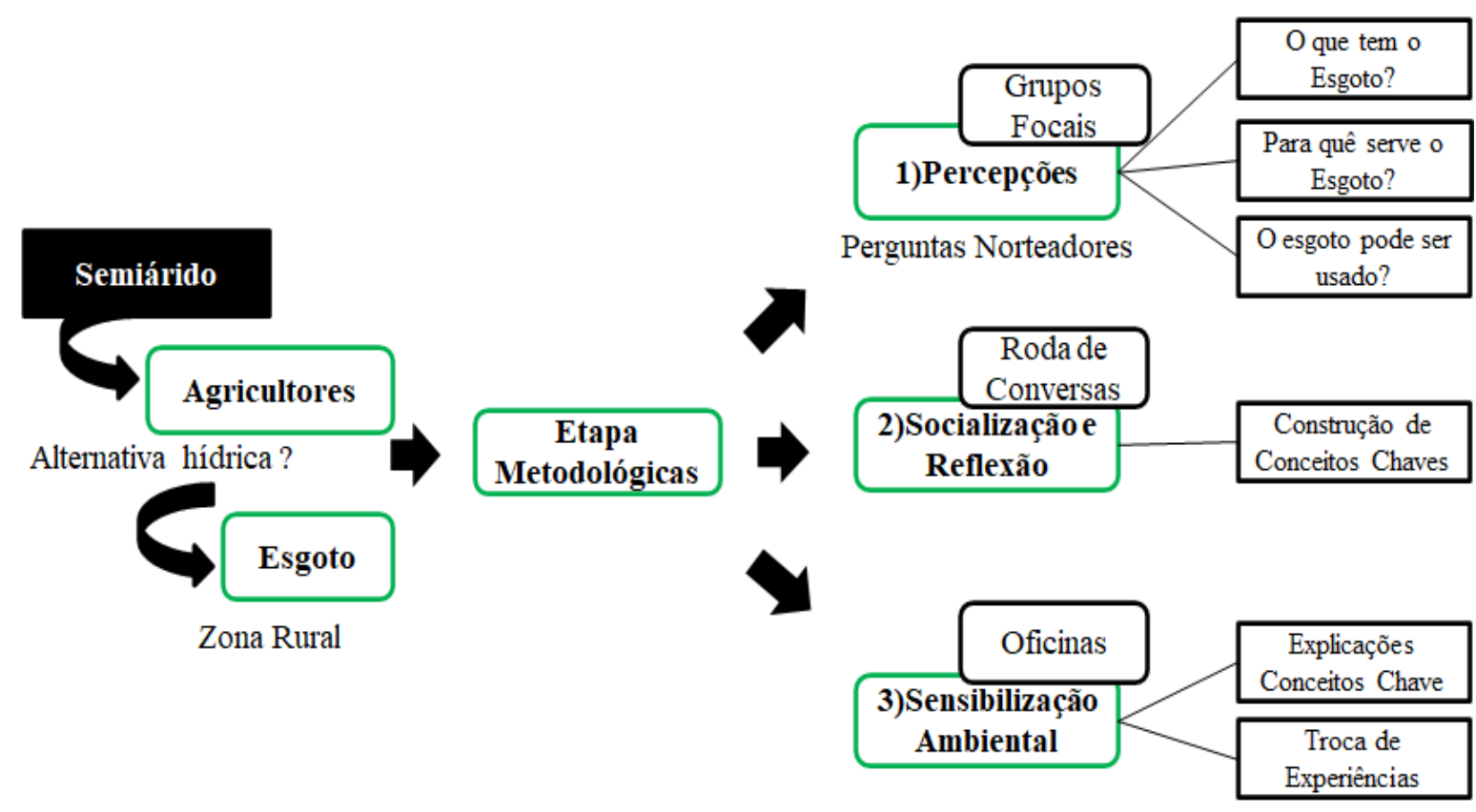

Figura 2: Fluxograma das etapas metodológicas da pesquisa.

Fonte: Autores, 2020.

Para o primeiro momento, os participantes foram subdivididos em grupos, e para investigar as percepções dos participantes utilizou-se a técnica de grupo focal (GF), que consiste em uma entrevista qualitativa de profundidade realizada com um grupo de pessoas, em nosso caso, agricultores de diferentes comunidades interagindo entre si para construção de informações de forma coletiva e dinâmica (OLIVEIRA, 2007).

Os GF foram mediados e o tempo monitorado para que durasse 30 minutos, mas permitindo a liberdade aos participantes para exposição das ideias, dúvidas e questionamentos, sobre as perguntas norteadoras: (i) o que tem no esgoto?, (ii) para que serve o esgoto? e (ii) o esgoto pode ser utilizado de qualquer jeito?.

Após a discussão e construção dos conceitos e respostas às perguntas norteadoras, realizou-se o segundo momento, com a socialização dos conceitos fomentados em cada grupo. Nesse momento, seguiu-se com a formação de uma roda de conversas, para buscar a interação entre os participantes de cada grupo e o pesquisador, com uma discussão norteada em tópicos específicos. Aqui os participantes são incentivados a emitirem suas opiniões e experiências (IERVOLINO, PELICIONI, 2001).

Por fim, com a base nas percepções, discussões e formulação dos conceitos, seguiu-se com a última etapa metodológica da pesquisa, que consistiu numa oficina pedagógica, a qual permite um prolongamento de sua atuação/formação inicial, com objetivo de aperfeiçoamento teórico-prático, além do exercício profissional em ações voltadas tanto na execução dentro da sua jornada de trabalho, quanto fora desta (KLEIN et al., 2005). 
Com o objetivo de compartilhar informações referentes a prática do reúso, foram realizadas explicações sobre os conceitos chaves já discutidos como a (i) diferenças dos tipos de efluentes para reúso (esgoto e água cinza), a (ii) importância do reúso na agricultura para regiões semiáridas, os (iii) riscos associados aos efluentes, (iv) técnicas de tratamento de esgoto para produção de um efluente seguro do ponto de vista sanitário e por fim as (v) experiências do Instituto Nacional do Semiárido e ações de tratamento e reúso agrícola como alternativa para preservação da saúde e do meio ambiente no semiárido.

Ao focarmos a temática na perspectiva ambiental trabalhando com as oficinas pedagógicas, buscou-se sensibilizar o olhar dos agricultores como sujeitos da ação, contextualizando e aproximando do seu cotidiano, envolvendo-o, para que participe, haja e transforme, promovendo trocas coletivas a integração e inserção das diferentes leituras de mundo, nas questões urgentes e essenciais (VEGA; SCHIRMER, 2008).

\section{Análise dos dados}

Para análise de dados, utilizou-se da abordagem qualitativa das informações, através de registros dos discursos dos participantes durante todo o trajeto da pesquisa, assim como foi feito registro por escrito dos conceitos formulados pelos participantes durante a formação dos grupos focais, da socialização e da reflexão das informações durante a roda de conversas entre os grupos. Durante as oficinas de sensibilização ambiental, com intuito de identificar aspectos relacionados à seletividade do efluente (esgoto e água cinza) utilizado, a destinação do reúso nas atividades diárias dos participantes, os riscos potenciais do uso, manejo e gestão, a viabilidade destas ações na contribuição para formação destes agricultores no convívio com semiárido e a disponibilidade de água de qualidade para suas atividades, focou-se na análise do discurso verbal dos participantes.

\section{Resultados}

\section{Caracterização social dos agricultores}

A maioria dos participantes foram do sexo feminino $(66,7 \%, n=10)$, enquanto os indivíduos do sexo masculino representaram $33,3 \%(n=5)$ dos participantes. Os agricultores participantes apresentaram idade variada com maior predominância de indivíduos femininos com idade inferior a 50 anos (Figura 3). A participação das mulheres demostra que cada dia mais as mulheres estão tendo um papel ativo e importante para o desenvolvimento sustentável, com o reconhecimento e crescimento da igualdade. 


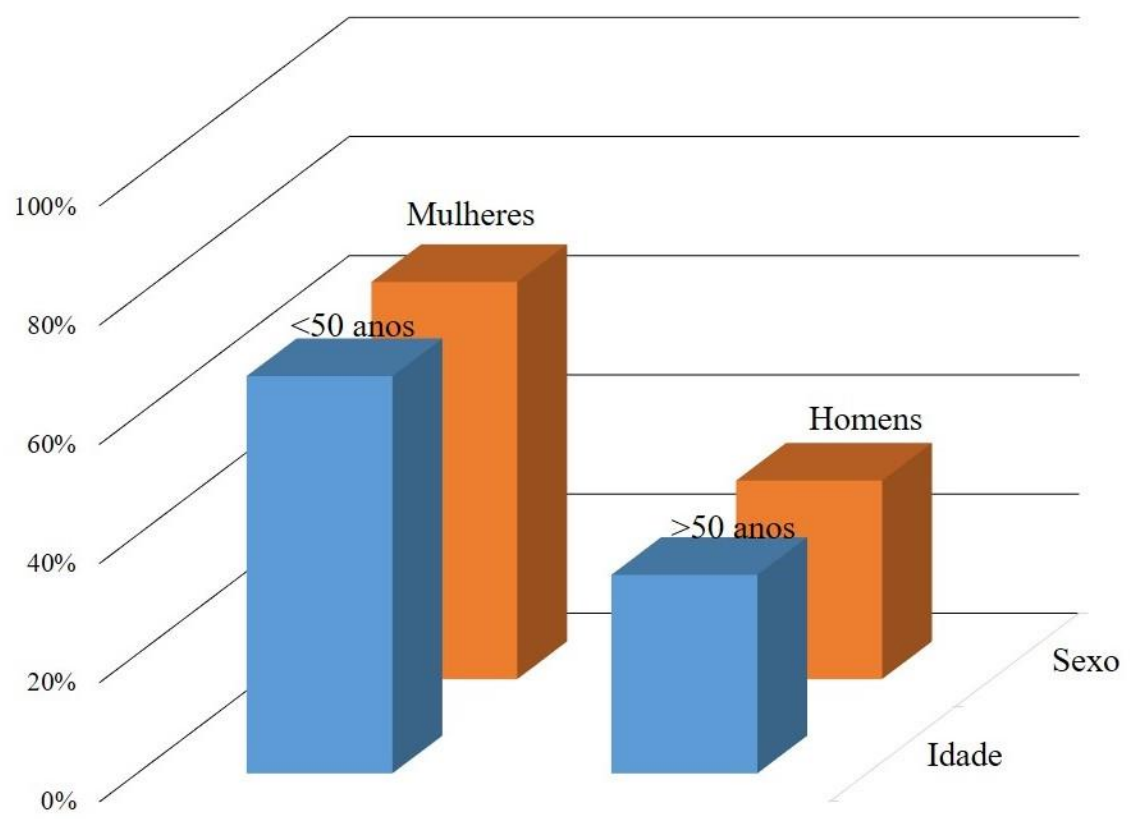

Figura 3: Caracterização social dos agricultores rurais do município de Assunção (PB).

Fonte: Autores, 2020.

\section{Percepção dos agricultores sobre práticas e manejo do reúso de água}

Com intuito de identificar as percepções dos agricultores sobre a oferta e demanda hídrica na comunidade, observou-se no discurso dos participantes, que unanimemente, devido ao difícil acesso a água de qualidade (potável) este recurso é reservado a usos mais nobres e fundamentais, como beber e cozinhar, tornando assim, o uso de outras fontes de água uma alternativa fundamental na manutenção do cotidiano da comunidade. A realidade hídrica e sanitária das áreas rurais do semiárido brasileiro, apresenta-se como um dos principais entraves de desenvolvimento, resultando ainda como fatores de risco para saúde dos moradores (MENDONÇA et al., 2012).

Na região semiárida, as principais fontes de água são pluviais e fluviais, através de mecanismos como a captação direta da água da chuva ou pelo barramento de rios, que em sua maioria são intermitentes que ao reduzirem seu volume perdem suas propriedades de abastecimento (ARAÚJO, 2012). A ausência da oferta de água encanada e saneamento básico destas áreas, faz com que as áreas rurais dos municípios do semiárido, sejam abastecidos, em parte ou totalmente, por formas alternativas (ex. chafariz, poço particular, carropipa, dessalinização, barreiros, cacimbas e etc), com isso a reduzida qualidade destas fontes tornam seus usos secundários. (IBGE, 2011; AZEVÊDO et al., 2017).

Além dos problemas estruturais relativos ao acesso a água e saneamento, as áreas rurais sofrem ainda com as condições climáticas, elevadas temperaturas e baixas precipitações, que limitam ainda mais e não suprem a demanda, desta forma ferramentas como o reaproveitamento e reúso 
de água tornam-se comuns (LUCENA et al., 2018). Em nosso estudo, pudemos identificar que os participantes já realizam a prática de reciclagem da água (Tabela 1) resultantes de atividades domésticas cotidianas (águas cinzas), uma vez que, o reúso da água ocorre internamente, tendo como objetivo a economia de água e o controle da poluição (SILVA; SANTANA, 2014).

Tabela 1: Caracterização das principais práticas de reúso de água realizadas por agricultores no semiárido

ORIGEM DA ÁGUA
FINS DE REAPROVEITAMENTO
Proveniente da lavagem de roupa

Proveniente do banho

Proveniente da lavagem de pratos
Lavagem de pisos

Descarga

Fonte: Autores, 2020.

Todas as práticas citadas são voltadas ao uso de águas cinzas, e não de águas negras (esgoto). Apesar das águas cinzas não possuir contribuição de águas do vaso sanitário (responsável pela maior carga patogênica do esgoto, resultante das fezes e urina), é importante ressaltar que as águas cinzas podem necessitar de tratamento para assim poder serem utilizadas, sendo este tipo de tratamento dependente da qualidade da água e da finalidade do reúso. De acordo com Hespanhol (2003) para se aplicar o reúso de águas cinza é necessário um conhecimento da qualidade física, química e microbiológica das águas.

Dentre as práticas citadas pelos agricultores, percebe-se a segregação de parte das águas resultante de uma atividade doméstica para um reúso não planejado, ou seja, o uso da água em uma outra atividade menos nobre, que não exige uma qualidade elevada da água. Figueiredo et al. (2019) mostraram que nas 125 comunidades rurais de Campinas - SP estudadas havia a separação das águas cinzas das atividades domésticas, sendo 91,2\% proveniente de lavanderia, $83,2 \%$ proveniente da pia da cozinha e $63,2 \%$ oriundas do banheiro (pia e chuveiro). Além disso, segundo os autores a prática é pouco documentada em artigos científicos e não há normas técnicas que fornecem diretrizes para o tratamento de efluentes em áreas que não atendidas por redes coletoras.

Vale ressaltar que as práticas de separação de água são bastante benéficas, uma vez que as águas cinzas apresentam menor concentração de patógenos, que as encontradas no esgoto bruto (contribuição do vaso sanitário), e assim ocorre a redução da vazão produzida e da carga poluidora. Segundo a Funasa (2015) numa perspectiva sustentável a separação das águas cinzas podem ser considerada um passo para o tratamento mais ecológico e eficiente do esgoto. 
Considerando as informações da Tabela 1 percebe-se que o reúso conhecido e aplicado pelos agricultores são voltados para as águas cinzas, e são resultantes de manejo de reúso de água cinza sem tratamento, ou seja, o reaproveitamento direto. Com relação ao esgoto nenhuma ação foi citada pelos agricultores, porém foi observado que os mesmos tem uma boa aceitabilidade para a possibilidade do reúso de esgoto.

Para analisar a percepção dos agricultores sobre o esgoto e alinhar com o aprofundamento da temática que envolve o reúso de efluente, foi realizado o GF (Figura 4) na qual foi perguntado aos participantes da oficina três questões fundamentais para se buscar desenvolver o reúso de efluentes (Tabela 2).

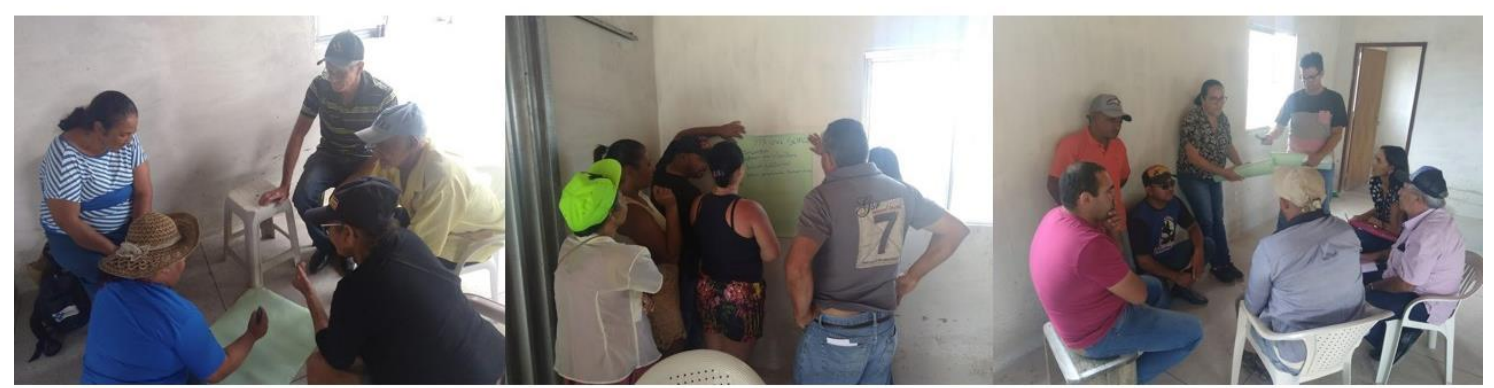

Figura 4: Grupo focais para avaliação da percepção dos agricultores sobre o esgoto.

Fonte: Autores, 2020.

Tabela 2: Caracterização da composição do esgoto na visão dos agricultores.

\begin{tabular}{|c|c|}
\hline Questionamentos & Percepção \\
\hline $\begin{array}{l}\text { O que tem no } \\
\text { esgoto? }\end{array}$ & $\begin{array}{l}\text { - Sabão, detergente, água sanitária, desinfetante, creme } \\
\text { - } \text { dental; } \\
\text { - Rerdura; } \\
\text { - } \text { Fezto de alimentos; } \\
\text { - Microrganismo; } \\
\text { - Fungos; } \\
\text { - Protozoários. }\end{array}$ \\
\hline $\begin{array}{c}\text { Para que serve o } \\
\text { esgoto? }\end{array}$ & $\begin{array}{l}\text { - Descarga; } \\
\text { - } \quad \text { Lguar as plantas; } \\
\text { - Lavar pisos e calçadas; } \\
\text { - Lavar a casa (águas de amaciante). }\end{array}$ \\
\hline $\begin{array}{l}\text { O esgoto pode ser } \\
\text { usado de qualquer } \\
\text { jeito? }\end{array}$ & $\begin{array}{l}\text { - Necessário realizar primeiro um tratamento; } \\
\text { - Utilizar o esgoto por sistema de irrigação de gotejamento. }\end{array}$ \\
\hline
\end{tabular}

Fonte: Autores, 2020.

Em análise às respostas obtidas sobre a percepção dos agricultores na constituição do esgoto (Tabela 2), a partir da formação de GF, foi observada uma heterogeneidade de pessoas com níveis de conhecimento mais aprofundado e aquelas com nível mais usual e popular. Isso porque é possível 
identificar respostas mais técnicas, como por exemplo as referentes aos grupos de microrganismos presente no esgoto que conferem riscos à saúde; que são eles: protozoários, vírus, bactérias e helmintos. Enquanto por outro lado, outras respostas citadas pelos agricultores estão associadas a alguma atividade do cotidiano, como por exemplo os vários produtos de limpeza e higiene pessoal, a gordura e resto de alimentos que são resultantes da lavagem de louça, e as fezes e urina que são oriundos do sistema digestivo humano. De maneira geral, percebe-se que há conhecimento do risco que o esgoto apresenta, mas pouco se conhece do seu potencial, quanto a uma fonte de água e nutrientes.

Analisando a percepção dos agricultores sobre o uso do esgoto, observa-se que algumas das atividades citadas são associadas a reciclagem de águas cinzas, sendo relacionadas às práticas por eles já desenvolvidas, como lavar pisos e calçadas, lavar a casa e utilizar para descarga em vasos sanitários. A transformação de águas residuárias (esgoto) em água de reúso deve atender aos padrões estabelecidos para utilização pretendida. Sendo assim, qualquer que seja a prática de reúso de esgoto é necessário o tratamento para atender as normas estabelecidas (SILVA; SANTANA, 2014), sendo no caso do reúso agrícola os padrões sanitários estabelecidos pela organização mundial de saúde (WHO, 2006).

Aqui percebe-se que grande parte dos agricultores não diferenciam o esgoto das águas cinzas, e principalmente não enxergam o reúso agrícola do esgoto como uma possibilidade praticável na realidade local. Vale ressaltar, que o reúso de esgoto pode ser uma alternativa sustentável para a população da zona rural, promovendo ações de saneamento básico por meio do tratamento de esgoto e promoção de água para utilização na agricultura, além da preservação da saúde e do meio ambiente.

Com relação a forma que o esgoto pode ser reutilizado, os agricultores participantes mostraram-se bastante consciente evidenciado a necessidade do tratamento para pode utilizá-lo. Apesar de não haver relatos sobre formas de tratamento do esgoto durante a roda de conversa, é possível observar que os agricultores conhecem o risco para a saúde se utilizar o esgoto sem tratamento. Outro fator abordado foi sobre uma das formas de reúso de esgoto na agricultura, irrigação por gotejamento, que é uma técnica simples, eficaz e segura de se utilizar o esgoto tratado, que permite a segurança da população trabalhadora na área, garante a qualidade hídrica e quantidade nutricional necessária à planta e não polui o ar como o caso dos sistemas por aspersão.

\section{Sensibilização ambiental}

Com o objetivo de sensibilizar os agricultores, realizou-se uma intervenção participativa por meio de um diálogo aberto sobre a composição (matéria orgânica, nutrientes e patógenos), riscos e manejo do esgoto, bem como as possibilidades de tecnologia de tratamento para esses efluentes visando o reúso agrícola. 
Tornando aplicável os conceitos construídos, demonstrou-se tecnologias acessíveis como tratamento de esgoto anaeróbio composta por filtro de areia e lagoa de estabilização, por ser uma técnica de baixo custo, de simples operação e manutenção, além de ser efetiva na remoção de matérias orgânica e microrganismos, garantindo a preservação dos nutrientes que são importantes para as práticas agrícolas, tornando-a assim, ideal a realidade dos agricultores. Ainda com objetivo (in)formativo destacou-se os riscos de se manusear e utilizar esses efluentes (água cinzas e esgoto) sem tratamento. Mostrando os impactos que podem causar ao solo e a planta, mas principalmente os riscos e doenças causadas pelos diversos microrganismos patogênicos.

Por fim, com intuito de promover ações das práticas apresentadas, foram demonstradas experiências com os sistemas de tratamento de efluente para reúso agrícola (reúso agrícola de águas cinzas tratadas e reúso agrícola de esgoto tratado), através das ações que vêm sendo desenvolvidas pelo Instituto Nacional do Semiárido (INSA), com o tratamento do esgoto do instituto para cultivo de palma forrageira. Outra prática apresentada através do depoimento (em vídeo), mostrando a experiência de uma família de agricultores com sistema de tratamento e reúso das águas cinzas para produção de diversas culturas, dentre elas as frutíferas. No vídeo foi mostrado todo o processo de montagem do sistema de tratamento e dos benefícios que a família pôde obter com o reúso de água.

\section{Conclusões}

O esgoto representa um recurso valioso que pode ser aproveitado na agricultura. Desse modo, a difusão de informações relacionados ao reúso de efluentes, seu potencial e os riscos associados, são fundamentais para um desenvolvimento sustentável. Na perspectiva do presente estudo, foi possível avaliar a percepção dos agricultores sobre o reúso, possibilitando identificar que as práticas por eles realizadas são voltadas ao reúso de água cinzas em outras atividades de usos menos nobres, mas não na irrigação.

Desse modo, a oficina buscou sensibilizá-los sobre os benefícios do esgoto como alternativa sustentável na agricultura, em especial para as áreas com déficits hídricos, como a zona rural. Mostrando as técnicas para o manuseio e uso adequado, bem como aplicações e experiências práticas realizadas por comunidades e famílias, proporcionando benefícios não só ao meio ambiente, mas sociais e econômicos para a população que utilizam o reúso agrícola de efluente.

\section{Agradecimentos}

À CAPES e ao MCTI pelo apoio financeiro pela concessão de bolsas

$$
\text { aos pesquisadores, ao INSA ao PATAC e aos agricultores pela parceria para a }
$$
realização do trabalho. 


\section{Referências}

ARAÚJO, J. C. Recursos hídricos em regiões semiáridas. In: GHEYI, H.R., PAZ, V.P.S., MEDEIROS, S.S., GALVÃO, C.O. (Editores), Recursos hídricos em regiões semiáridas. Campina Grande, PB: Instituto Nacional do Semiárido, p. 258, 2012.

AZEVÊDO, E. L.; ALVES, R. R. N.; DIAS, T. L. P.; MOLOZZI, J. How do people gain access to water resources in the Brazilian semiarid (Caatinga) in times of climate change? Environmental monitoring and assessment, $v$ 189, n 375, p. 8, 2017.

BARROS, H. M. M.; VERIATO, M. K. L.; SOUZA, L. P.; CHICÓ, L. R.; BAROSI, K. X. L. Reúso de água na agricultura. Revista Verde de Agroecologia e Desenvolvimento Sustentável, v 10, n 5, p. 11 - 16, 2015.

CPRM - Serviço Geológico do Brasil. Projeto cadastro de fontes de abastecimento por água subterrânea. Diagnóstico do município de Assunção, Estado da Paraíba. Recife: CPRM/PRODEEM, 2005.

FIGUEIREDO, I. C. S.; DUARTE, N. C.; COASACA, R. L.; MAGALHÃES, T. M.; BARBOSA, A. C.; PORTELA, D. G.; MADRID, F. J. P. L.; OLIVEIRA CRUZ, L. M. O.; TONETTI, A. L. Águas cinzas em domicílios rurais: separação na fonte, tratamento e caracterização. Revista DAE, v. 67, n. 220, 2019.

FUNASA. Fundação Nacional de Saúde. Manual de Saneamento. Ministério da Saúde, Fundação Nacional de Saúde. 4ª ed. Brasília: Funasa, 2015.

GOOGLE MAPS. Disponível em:<https://www.google.com/maps/> Acesso em 20 de agosto de 2020.

HESPANHOL, I. Potencial de reuso de água no Brasil: agricultura, indústria, município e recarga de aquíferos. In: MANCUSO, P. C. S.; SANTOS, H. F. (Ed.). Reuso de Água. Barueri, SP: Manole, 2003. Cap. 3, p. 37-95.

IERVOLINO, S.A.; PERLICIONI, M.C.F.A. Utilização do grupo focal como metodologia qualitativa na promoção da saúde. Revista Escola de Enfermagem, v.35, n. 2, p. 115-21, 2001.

Instituto Brasileiro de Geografia e Estatística (IBGE). Cidades e Estados. Disponível em <https://www.ibge.gov.br/cidades-eestados.html?view=municipio $>$ Acesso em 29 de maio de 2020.

KLEIN, T. A. S.; OLIVEIRA, V. L. B.; PEGORARO O. M. E.; CUPELLI, R. L. Oficinas pedagógicas: uma proposta para a formação continuada de professores de biologia. Anais do $\mathrm{V}$ Encontro Nacional de Pesquisa em Educação em Ciências, n5, 2005, p. 1-7

LUCENA1, C, Y, S.; SANTOS1, D, J, R.; SILVA1, P, L, S.; COSTA1, E, D.; LUCENA2, $R$, $L$. O reuso de águas residuais como meio de convivência com a seca no semiárido do Nordeste Brasileiro. Revista de Geociências do Nordeste, v. 4, 2018. 
MEDEIROS, S. S.; SALCEDO, I. H.; SANTOS, D. B.; BATISTA, R. O.; SANTOS JUNIOR, J. A.; LIMA, R. C. C.; PEREZ-MARIN, A. M. Esgotamento Sanitário: Panorama para o Semiárido Brasileiro. 1. ed. Campina Grande: Instituto Nacional do Semiárido, 2014. v. 1. 63p.

MENDONÇA, Z. C. L.; CANDEIAS, A. L. B.; SELVA, V. F.; SILVA, M. M.; RODRIGUES, G. G.; SANTOS, S. M. Aspectos Sanitários e de Uso da Água em Pequenas Comunidades Rurais do Semiárido Pernambucano. Revista Brasileira de Geografia Física, v.5, 2012, p. 1191-1202.

METCALF \& EDDY. Tratamento de efluentes e recuperação de recursos. Tradução: Ivanildo Hespanhol, José Carlos Mierzwa. 5. ed. Porto Alegre: AMGH, 2016.

OLIVEIRA, M. S. Educação Ambiental e organizações da sociedade civil da Bacia Hidrográfica do Córrego Água Quente (São Carlos/SP): compreendendo a incorporação da temática ambiental em suas ações sócio-educativas. $151 \mathrm{f}$. 2007. Dissertação (Mestrado em Ciências da Engenharia Ambiental) - Escola de Engenharia de São Carlos, Universidade de São Paulo, São Carlos, 2007. Disponível em: Acesso em

OLIVEIRA, M. S. Metodologia Científica: um manual para a realização de pesquisas em administração. 2007. 72 p.: il. 151f. 2007. (Pós-graduação em administração) - Universidade Federal de Goiás, 2011.

PAZ, V. P. S.; TEODORO, R. E. F.; MENDONÇA, F. C. Recursos hídricos, agricultura irrigada e meio ambiente. Revista Brasileira de Engenharia Agrícola e Ambiental, v.4, n 3, 2000.

ROMÃO, E. L.; BARGOS, D. C.; SILVA, L. A. G.; MELO, L. R. Percepção ambiental de alunos de graduação em engenharia sobre a importância da educação ambiental. Revista Brasileira de Educação Ambiental, v 15, n 1, p 194-208, 2020.

SILVA, M. A.; SANTANA, C. G. REUSO DE ÁGUA: possibilidades de redução do desperdício nas atividades domésticas. Revista do Centro de Estudos em Desenvolvimento Sustentável da UNDB, n.1, 2014.

SUDENE. MINISTÉRIO DA INTEGRAÇÃO NACIONAL SUPERINTENDÊNCIA DO DESENVOLVIMENTO DO NORDESTE CONSELHO DELIBERATIVO. Estabelece critérios técnicos e científicos para delimitação do Semiárido Brasileiro e procedimentos para revisão de sua abrangência. Resolução № 107, DE 27 DE JULHO DE 2017.

VEGA, L. B. da S.; SCHIRMER; S. N. Oficinas ecopedagógicas: transformando as práticas educativas diárias nos anos iniciais. Revista Eletrônica do Mestrado em Educação Ambiental, v. 20, p. 393-408, 2008.

WHO, 2006. Guidelines for the Safe Use of Wastewater, Excreta and Greywater. World Health Organization, Geneva. 